\title{
50 Anniversary of Nobel Prize for Polarography
}

\author{
Jiř́ Barek \\ Department of Analytical Chemistry, Faculty of Science, Charles University, \\ Prague, Czech Republic (barek@natur.cuni.cz)
}

On December 10th, 1959 Professor Jaroslav Heyrovský received from the hands of King of Sweden Gustav Adolph VI Nobel Prize (Fig. 1) "for his discovery of polarographic method of analysis" as stated on the certificate (Fig. 2). To commemorate this event, this article pays attention both to the history and to the significance and future of polarography.

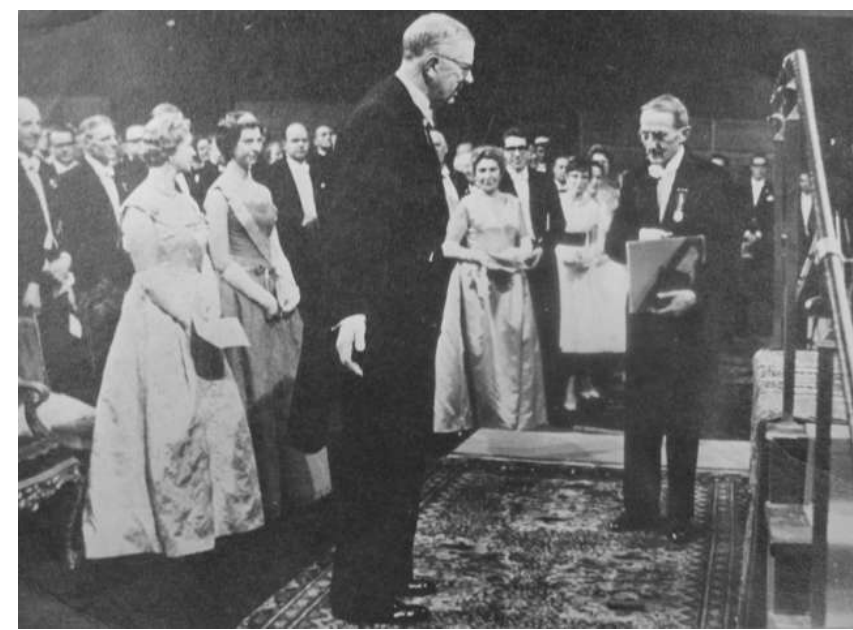

Fig. 1. Professor Heyrovský receives Nobel Prize for polarographic method of analysis.

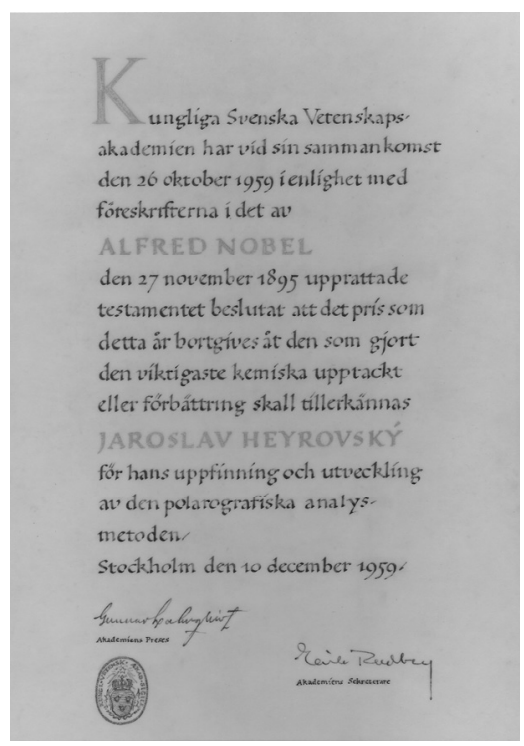

Fig. 2. Nobel Prize certificate.

\section{Invention of polarography}

At the beginning of the twenties of the last century, Professor Heyrovský carried out a research on electrocapillary curves using mercury dropping into an electrolyte solution. He developed a modification based on measurement of the drop-time instead of the drop weight which shortened the time spent by drying and weighing mercury drops. On Fig. 3 we can 
see a kind of birth certificate of polarography - a copy of the page of Professor Heyrovský laboratory notebook from January 9, 1922. On that day professor Heyrovský wrote the sentence "all must be done with the galvanometer" clearly formulating his pioneering idea to measure the current flowing through the dropping mercury electrode. The next day he measured the first dependence of the current flowing through the dropping mercury electrode on the applied potential and drew a corresponding graph in his laboratory notebook which can be considered as the first polarogram (Fig. 4). The observed current increases corresponded to the stepwise reduction of oxygen around $-0.1 \mathrm{~V}$ and $-1.0 \mathrm{~V}$ and to the reduction of sodium around $-2.0 \mathrm{~V}$. Prof. Heyrovský soon recognized the analytical potential of the new method and realized that point-by-point measurements and plotting of current-voltage curves was tedious and time consuming and together with M. Shikata (see Fig. 5) constructed a new instrument, which was later called polarograph, that recorded photographically such a curve in several minutes (see Fig. 6). (For details, see ref. [1]).

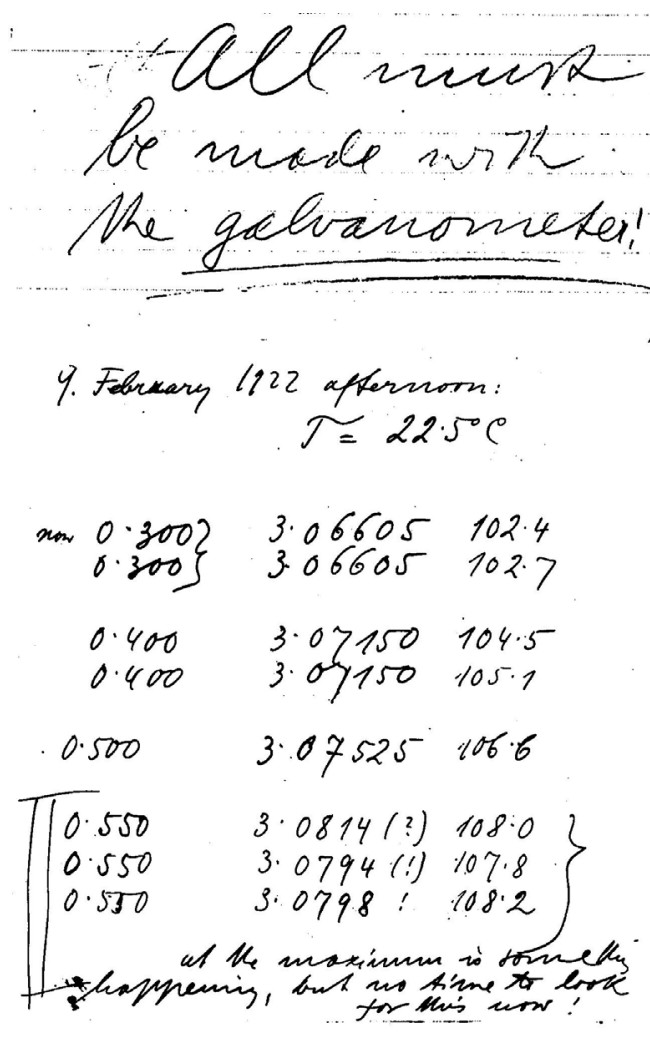

Fig. 3. Copy of the page from Professor Heyrovský laboratory notebook.

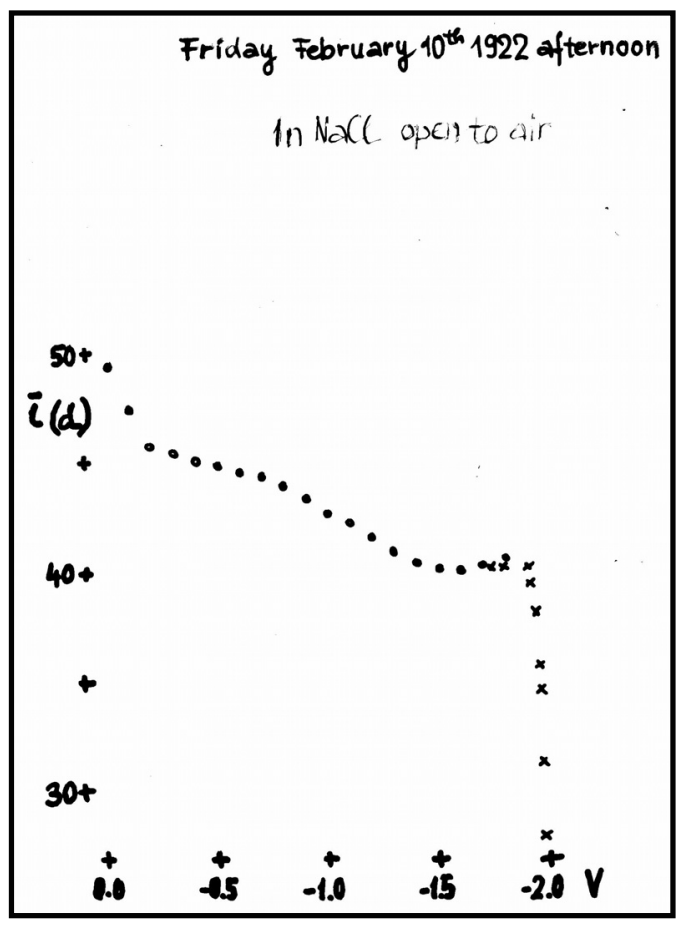

Fig. 4. The first recorded $I-E$ curve copied from professor Heyrovský's laboratory notebook. 


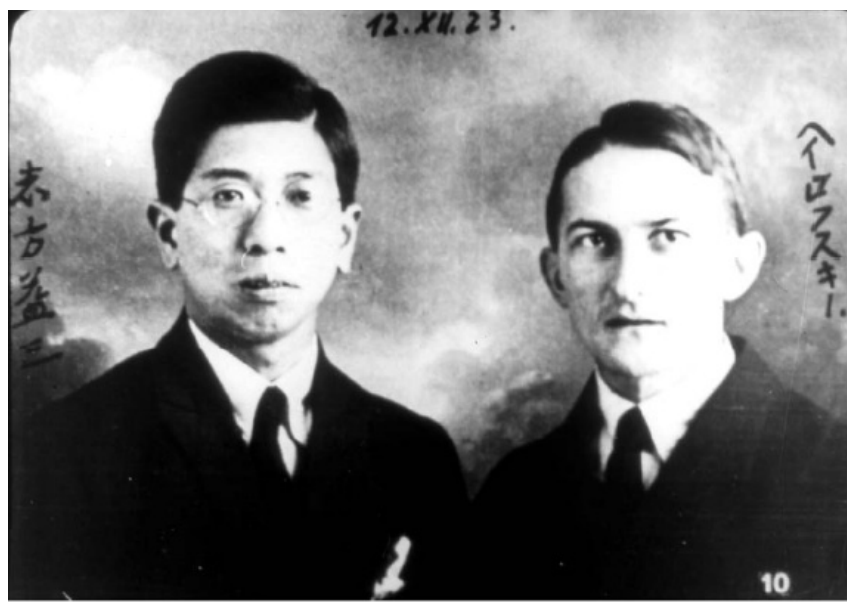

Fig. 5. Professor Heyrovský and Professor Shikata in 1923.

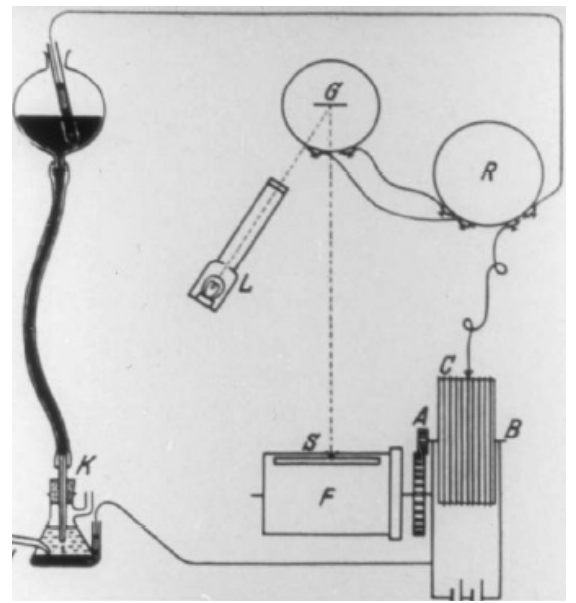

Fig. 6. Scheme of the first photorecording Polarograph.

\section{Development of polarography}

Further development proceeded in three parallel lines: development of mercury electrodes (from classical dropping mercury electrode through mercury streaming electrode, hanging mercury drop electrode, static mercury drop electrode, mercury film electrode, mercury amalgam electrodes, mercury microelectrodes, chemically modified mercury electrodes, controlled growth mercury electrodes and contractible mercury drop electrodes), development of measuring techniques (from classical DC polarography through oscillopolarography, Kalousek's switcher, AC polarography, tast polarography, normal pulse polarography, differential pulse polarography, square-wave voltammetry, cyclic voltammetry, anodic stripping voltammetry, adsorptive stripping voltammetry, convolution techniques and elimination methods) and development of preconcentration techniques on the surface of mercury electrodes enabling a substantial increase of sensitivity which proceeded from anodic striping voltammetry and cathodic striping voltammetry to adsorptive stripping voltammetry. (for details, see refs [2,3]). Professor Heyrovský very soon recognized the importance of potential and its control, analytical opportunities offered by measuring the limiting currents and pointed out that the position of the wave on the potential axis is characteristic of the reduced species and can be used for qualitative analysis. He was an enthusiastic propagator of polarography capable to explain the method in simple terms, which helped its acceptance as an acknowledged analytical method in routine laboratories. He continually explained both the theoretical and practical possibilities offered by this technique and the application of 
polarography in practical analysis and for solution of practical problems. He created in Prague a center of polarographic research and created a scientific school, which substantially influenced both electrochemistry and analytical chemistry. The Nobel Prize award in 1959 for polarography as an analytical method was thus very well deserved.

\section{Present state and future of polarography}

Because of strong competition of extremely powerful spectrometric and separation techniques, polarography is nowadays not too frequently used in routine analytical laboratories. Nevertheless, the author of this article strongly believes that even today polarography can be useful because of extremely broad linear dynamic range and low limit of determination from $10^{-7} \mathrm{M}$ for pulse techniques down to $10^{-11} \mathrm{M}$ for stripping techniques [4], low running and investment costs, high speed and easy automation, diversity of determinable analytes and reasonable selectivity especially in combination wit a suitable method of preliminary separation and sample clean-up. Thousand of reliable polarographic methods available in scientific literature together with the fact that around 300 new polarographic methods are published every year confirms that in many cases polarography can even today present a viable alternative to other instrumental methods. Mercury electrodes are still among best available in electroanalytical chemistry because of their atomically smooth surface, easily renewable surface and broad cathodic potential window. For that reason it can be expected that even in the future they will be used for mechanistic studies especially of organic compounds (this is important for basic research, structure-activity relationship investigation, study of supramolecular interactions, etc.), for trace metal determination and speciation (important for bioavailability studies and for soil and water analysis), for trace determination of organic compounds (in environmental, toxicological and pharmaceutical analysis), for voltammetric immunoassays, for nucleic acid research and for screening methods and large scale monitoring of selective polarographically reducible substances. Moreover, the enthusiasm of innovative electrochemists will be the main driving force of future development as it used to be in the pioneering times of Professor Heyrovský.

\section{Acknowledgement}

Our research on polarography and voltammetry is supported by the Ministry of Education, Youth and Sports of the Czech Republic (projects LC 06035 and MSM 0021620857). 


\section{References}

[1] Zuman P.: Electrolysis with a Dropping Mercury Electrode: J. Heyrovsk'y's Contribution to Electrochemistry. Crit. Rev. Anal. Chem. 2001, 31, 281.

[2] Barek J., Fogg A.G., Muck A., Zima J.: Polarography and Voltammetry at Mercury Electrodes. Crit. Rev. Anal. Chem. 2001, 31, 291.

[3] Barek J., Zima J.: Eighty Years of Polarography - History and Future. Electroanalysis 2003,15, 467.

[4] Barek J., Pecková K., Vyskočil V.: Adsorptive Stripping Voltammetry of Environmental Carcinogens. Curr. Anal. Chem. 2008, 4, 242.

\section{（イリ バレック）}

Prof. RNDr. Jiř́i Barek, CSc.

Head of the Department of Analytical Chemistry,

Faculty of Science, Charles University, Albertov 6, 12843 Prague 2, Czech Republic.

e-mailBarek@natur.cuni.cz 